\title{
FATORES DE (IN)SATISFAÇÃO NO TRABALHO DA EQUIPE DE ENFERMAGEM EM UTI PEDIÁTRICA
}

Pâmela de Pol${ }^{1}$, Lidia Dalgallo Zarpellon², Graciele de Matia ${ }^{3}$

\begin{abstract}
RESUMO: Estudo utilizou abordagem qualitativa do tipo exploratório-descritivo e teve como objetivos investigar os fatores que contribuem para a satisfação e para a insatisfação no trabalho da equipe de enfermagem em Unidade de Terapia Pediátrica e propor estratégias de abordagem que favoreçam a satisfação em seu trabalho, segundo a percepção dos próprios membros da equipe. A coleta de dados foi realizada com 18 profissionais atuantes em UTI Pediátrica de dois hospitais do município de Curitiba-Paraná, de fevereiro a maio de 2011, utilizando-se a entrevista semiestruturada. Os resultados foram analisados utilizando a técnica de análise de conteúdo e mostram a percepção da complexidade que envolve ser profissional de enfermagem atuante em terapia intensiva, apontando e levando à reflexão sobre a relação dialógica entre cuidar e ser cuidado. DESCRITORES: Equipe de enfermagem; Unidades de terapia intensiva pediátrica; Satisfação no emprego; Motivação; Papel do profissional de enfermagem.

\section{FACTORES DE (IN) SATISFACCIÓN EN EL TRABAJO DEL EQUIPO DE ENFERMERÍA EN UTI PEDIÁTRICA}

RESUMEN: Estudio de abordaje cualitativo del tipo exploratorio descriptivo. Tuvo como objetivos investigar los factores que contribuyen para la satisfacción y para la insatisfacción en el trabajo del equipo de enfermería en Unidad de Terapia Pediátrica, así como proponer estrategias de abordaje que favorezcan la satisfacción en en trabajo, de acuerdo con la percepción de los propios miembros del equipo. Los datos fueron obtenidos con 18 profesionales actuantes en UTI Pediátrica de dos hospitales del municipio de Curitiba - Paraná, de febrero a mayo de 2011, utilizándose la entrevista semiestructurada. Los resultados fueron examinados por medio de la técnica de análisis de contenido y muestran la percepción de la complejidad de ser profesional de enfermería actuante en terapia intensiva, apuntando y promoviendo la reflexión sobre la relación de diálogo entre cuidar y ser cuidado. DESCRIPTORES: Equipo de enfermería; Unidades de terapia intensiva pediátrica; Satisfacción en el empleo; Motivación; Papel del profesional de enfermería.

\section{FACTORS OF (DIS)SATISFACTION IN THE WORK OF THE NURSING TEAM IN PEDIATRIC ICU}

\begin{abstract}
This study used a qualitative approach of the exploratory-descriptive type and aimed to investigate the factors which contribute to the nursing team's work satisfaction and dissatisfaction in the Pediatric Intensive Care Unit, and to propose approach strategies which promote satisfaction in work, according to the perception of the team members themselves. Data collection was undertaken with 18 professionals working in Pediatric ICU in two hospitals in the city of Curitiba in the state of Paraná between February and May 2011, using semi-structured interviews. The results were analyzed using the technique of content analysis and show the perception of the complexity which is involved in being a nursing professional working in intensive care, indicating and leading to reflection on the dialogic relationship between caring and being cared for. DESCRIPTORS: Nursing team; Pediatric intensive care unit; Work satisfaction; Motivation; Role of the nursing professional.
\end{abstract}

${ }^{1}$ Enfermeira. Hospital Universitário Cajuru. Curitiba-PR-Brasil

${ }^{2}$ Enfermeira. Mestre em Educação. Professora da Universidade Estadual de Ponta Grossa. Ponta Grossa-PR-Brasil

${ }^{3}$ Enfermeira. Especialista em Administração Hospitalar e Clínicas, Formação Pedagógica para Profissionais da Área da Saúde e Metodologias Ativas. Professora da Faculdades Pequeno Príncipe. Curitiba-PR-Brasil

Autor correspondente:

Recebido: 06/02/2013

Graciele de Matia

Aprovado: 14/11/2013

Faculdades Pequeno Príncipe

Condomínio Paraíso do Bosque, 359 - 82220-260 - Curitiba-PR-Brasil

E-mail: graciele.matia@ig.com.br 


\section{INTRODUÇÃO}

O trabalho ocupa um lugar central na vida de todos e não poderia ser diferente para o profissional de enfermagem que, dependendo da forma como é executado e organizado, das condições oferecidas demanda ações, no sentido de suprir suas necessidades, as quais podem gerar sentimentos de satisfação ou insatisfação no ambiente de trabalho. No cotidiano prático da enfermagem, caracterizado por atividades que exigem alta interdependência, a motivação surge como aspecto fundamental na busca de maior eficiência e consequentemente, de maior qualidade na assistência prestada, aliada à satisfação dos trabalhadores.

O nível de satisfação profissional vem se tornando fator essencial e determinante para melhor entendimento do cuidado. A insatisfação com o ambiente de trabalho é uma questão que pode afetar a harmonia e a estabilidade psicológica do local, sendo que a satisfação/motivação do profissional se torna primordial para a assistência dos pacientes, principalmente na Unidade de Terapia Intensiva (UTI), onde se encontram pacientes potencialmente mais graves. Fatores como insatisfação no trabalho podem interferir na qualidade da assistência prestada aos pacientes, os quais devem receber, primordialmente, o cuidado com qualidade que inclui "um nível de excelência profissional, o uso eficiente de recursos, um mínimo de risco ao paciente/família e um alto grau de satisfação por parte dos usuários"(1:235).

O presente estudo teve como objetivos investigar os fatores que contribuem para a satisfação e para a insatisfação no trabalho da equipe de enfermagem em UTI Pediátrica e propor estratégias de abordagem que favoreçam a satisfação em seu trabalho, segundo a percepção dos próprios membros da equipe.

\section{MÉTODO}

Caracteriza se por um estudo de natureza qualitativa do tipo exploratório-descritivo. Qualitativa porque responde as questões muito particulares, abordando uma realidade que não visa a quantidade e sim adquirir o significado de relações e estruturas sociais. $\mathrm{O}$ número de participantes foi definido pela saturação das informações, totalizando 18 profissionais, incluindo enfermeiros, técnicos e auxiliares de enfermagem atuantes em UTI Pediátrica de duas unidades hospitalares do município de Curitiba, sendo uma pública e a outra filantrópica. Para melhor visualização e compreensão dos discursos obtidos, as identidades dos participantes foram omitidas, utilizou-se codinomes de sentimentos e emoções, seguidos da sigla F (Filantrópica) ou $\mathrm{P}$ (Pública) conforme a instituição.

A abordagem com os entrevistados ocorreu após um contato prévio, sendo questionados sobre o interesse na participação do estudo, esclarecendo os propósitos do trabalho. Após o aceite, todos os participantes assinaram o Termo de Consentimento Livre e Esclarecido, seguindo os preceitos da Resolução 196/96 do Conselho Nacional de Saúde, que vigorava no período de desenvolvimento do trabalho. O período de coleta dos dados ocorreu de fevereiro a maio de 2011. Foi utilizado um roteiro de entrevista semiestruturada com questões abertas, gravada, de acordo com os objetivos do estudo, cada funcionário foi entrevistado uma única vez, não foi estabelecido tempo limite para a duração da entrevista.

As questões abertas foram: $\mathrm{O}$ que significa para você satisfação no ambiente de trabalho? O que significa para você insatisfação no ambiente de trabalho? Como você se sente em seu ambiente de trabalho atualmente? Por quê? Que elementos contribuem para que a satisfação ou a insatisfação ocorram no ambiente de trabalho? Qual sua contribuição para que as insatisfações sejam minimizadas? Como o enfermeiro poderia colaborar no ambiente de trabalho para que sua equipe se sinta mais motivada?

Os critérios de inclusão foram: ser enfermeiro, técnico ou auxiliar de enfermagem, aceitar participar voluntariamente da pesquisa; atuar em UTI Pediátrica com no mínimo um ano de experiência no setor. Não foram consideradas variáveis de gênero, cor, raça ou idade.

Para o processo de análise das informações foi utilizada a técnica de análise de conteúdo ${ }^{(2)}$, observando as fases propostas: pré-análise, exploração do material e tratamento dos resultados, inferência e interpretação. As falas foram divididas em unidades de contexto e registro, e organizadas em unidades de contexto.

\section{RESULTADOS}

Na UTI Pediátrica do Hospital Filantrópico atuam 91 profissionais, a maioria técnicos em enfermagem, atendendo pacientes de 30 dias a 17 anos 11 meses e 29 dias, com um total de 30 leitos, apenas 24 ativos, devido a falta de recursos humanos e materiais. Já na UTI Pediátrica do Hospital Público atuam 25 funcionários, sendo também a maioria técnicos de enfermagem. Esta UTI Pediátrica atende pacientes de 28 dias a 14 anos incompletos, é de referência e classificada como tipo III pela Secretaria Estadual de Saúde, possui 10 
leitos com apenas seis ativos, devido à falta de recursos humanos e materiais.

Quanto aos profissionais entrevistados, foram abordados cinco enfermeiros, sete técnicos e seis auxiliares de enfermagem, de diferentes turnos, sendo nove de cada instituição. Observa-se que nas UTI a porcentagem de enfermeiros é inferior aos demais membros da equipe de enfermagem, cabendo a ele, frequentemente, atividades de gerenciamento e supervisão. Em relação ao gênero, a totalidade dos participantes era feminino, característica histórica da enfermagem.

A idade dos participantes variou de 20 a 59 anos. A Instituição Filantrópica conta com a maioria de seus profissionais de enfermagem com tempo de atuação em UTI entre um e cinco anos; na Instituição Pública os profissionais atuam de seis anos a 21 anos.

A partir da análise de conteúdo emergiram duas unidades de contexto: A) Motivações internas e externas da equipe de enfermagem quanto a (in) satisfação na atuação profissional em UTI Pediátrica; B) Estratégias que favoreçam a satisfação no trabalho da equipe de enfermagem.

\section{Motivações internas e externas da equipe de en- fermagem quanto a (in)satisfação na atuação pro- fissional em UTI Pediátrica - Unidade de Registro 1: Fatores de (in)satisfação em relação aos motivos externos provenientes do ambiente de trabalho.}

Começando pelo nível hierárquico da organização, primeiramente, destacamos a instituição como fator que gera insatisfação nos profissionais, conforme o discurso abaixo:

O que te faz desanimar são as cobranças da instituição mais a do familiar. As cobranças da instituição é tanta coisa, é o uniforme, é alguma coisinha que você faz com o paciente que não podia ser feito, dai a família reclama, e nunca ninguém tá satisfeito, só reclama, ninguém nunca agradece [...]. (Equilíbrio - F, técnica de enfermagem)

Outro fator de relevância presente nos discursos é quanto ao salário oferecido pela instituição (Filantrópica) e benefícios, que ao mesmo tempo podem trazer a satisfação dos que recebem mais benefícios como à insatisfação profissional para os que não recebem:

Acho que o salário conta bastante pra insatisfação, beneficios que você tem, algumas coisas que alguns funcionários mais antigos tem e outros que já entram agora não tem mais [...]. (Empatia - F, enfermeira)

Eu acho que no momento seria mais o salário, porque o salário está acontecendo o que, muito rodízio de funcionários, acaba estressando os que já trabalham, porque é muitorodízio[...]. (Honestidade-F, técnica de enfermagem)

A não existência de um local de descanso durante o período de trabalho e a escolha do dia de folga também são fatores de insatisfação conforme os relatos abaixo:

O pessoal reclama bastante que não tem um local adequado para o horário de descanso, então isso faz com que o povo esteja bem insatisfeito também [...]. (Empatia - F, enfermeira)

A insatisfação ocorre também porque às vezes a gente quer uma folga e não consegue, é difícil colocar outra enfermeira no nosso lugar na nossa folga, geralmente quando é final de semana e a gente precisa folgar já tem fila [...]. (Inteligência - F, enfermeira)

Há fatores que concorrem para a satisfação profissional, como expressam os participantes abaixo em relação aos recursos humanos e materiais, além das barreiras burocráticas:

Você ter equipamentos de proteção, é ter equipamentos adequados para você prestar assistência também é importante [...]. (Alegria - P, auxiliar de enfermagem)

A equipe de enfermagem relata também a importância de "gostar do que se faz" e de saber fazer com qualidade. Percebe-se que o apreço à profissão faz com que desempenhem suas atividades profissionais com prazer e prestem assistência de qualidade, e isso é um dos motivos de mais satisfação dentro do ambiente de trabalho conforme o discurso abaixo:

A primeira coisa, eu gosto de trabalhar demais aqui na UTI, todo o meu tempo assim de trabalho foi voltado mais para o trabalho com as crianças, e o que contribui é isso [...]. (Gratidão - P, técnica de enfermagem)

O trabalho desencadeia diferentes graus de (in) satisfação e (des)motivação, principalmente quanto a forma e ao meio em que ele é desenvolvido. Para os profissionais de enfermagem, a satisfação no ambiente de trabalho envolve: 
Satisfação é, ter uma equipe de trabalho primeiramente, porque mesmo que a situação no ambiente de trabalho não seja muito favorável, não tenha muitas condições de trabalho, mas tento uma boa equipe de trabalho, tudo funciona melhor [...]. (Amor - P, auxiliar de enfermagem)

Motivações internas e externas da equipe de enfermagem quanto a (in)satisfação na atuação profissional em UTI Pediátrica - Unidade de Registro 2: Fatores de (in)satisfação em relação aos motivos internos de cada profissional.

Para uma pessoa sentir-se satisfeita no cotidiano do trabalho há de se considerar o seu mundo pessoal, conforme as falas abaixo:

Primeiro o funcionário mesmo se ele gosta ou não do que ele faz [...]. (Esperança - F, técnica de enfermagem)

Para que esta satisfação aconteça, a pessoa tem que estar bem com ela mesma, porque queira ou não, é difícil você separar sua vida pessoal da vida profissional, então se ela não tá bem com ela mesma, também vai refletir no ambiente de trabalho[...]. (Verdade - F, enfermeira)

Dessa maneira pontua-se uma série de fatos, recursos, sentimentos e situações que abarcam a dimensão da satisfação e insatisfação:

Satisfação no ambiente do trabalho, é poder vir ao trabalho, né, executar minhas funções com qualidade e sentir que eu não só cumpri com trabalho que eu vim fazer, é, como também contribuir de alguma forma para o serviço da equipe assim, adoro trabalhar aqui [...]. (Paz - P, técnica de enfermagem).

Insatisfação acho que é quando você vem, mas acho que não consegue realizar aquilo que você gostaria, se você quer fazer além do que vocêfaz e muitas vezes você não consegue [...]. (Vigor - $\mathrm{P}$, enfermeira)

Motivações internas e externas da equipe de enfermagem quanto a (in)satisfação na atuação profissional em UTI Pediátrica - Unidade de Registro 3: Sentimentos apreendidos pela equipe referente ao ambiente de trabalho.

A maioria dos profissionais, apesar de referirem sentimentos de insatisfação, se sentem satisfeitos com o ambiente de trabalho atualmente, conforme os discursos abaixo:

Eu me sinto realizada, me sinto capaz de todas as funções que eu faço, mas sempre aprendendo mais [...]. (Honestidade - F, técnica de enfermagem)

Eu me sinto bem, dá para dizer que bem, tem algumas coisas ou outras que as vezes a gente não gosta mas não é contínuo, é normal, então eu atualmente me sinto bem [...]. (Justiça - P, auxiliar de enfermagem)

Estratégias que favoreçam a satisfação no trabalho da equipe de enfermagem - Unidade de Registro 4: Contribuição individual para que as insatisfações sejam minimizadas no ambiente de trabalho.

Os profissionais da equipe de enfermagem demonstram quais atitudes tomam para que as insatisfações no ambiente de trabalho sejam minimizadas:

Eu tento cumprir o meu papel de enfermeira aqui dentro da UTI, faço o que eu posso e às vezes até o que eu não posso [...]. (Inteligência - F, enfermeira)

Tentar sempre resolver as coisas, nunca adiar para resolver as dificuldades, procurar conversar, um diálogo é a melhor solução para as coisas [...]. (Persistência - P, técnica de enfermagem)

Estratégias que favoreçam a satisfação no trabalho da equipe de enfermagem - Unidade de Registro 5: Valorização do profissional em seu ambiente de trabalho.

Foi possível perceber que os entrevistados levantaram como ponto principal para sua motivação o reconhecimento profissional que consideram ser necessários para trazer mais satisfação no seu trabalho na UTI:

A gente é mais valorizado pelos pais do que pela equipe, porque você sabe que você precisa estar ali, ninguém fala para você "nossa seu trabalho é bom, como você trabalha bem" [...]. (Esperança - F, técnica de enfermagem)

Primeiro o reconhecimento da própria equipe, tanto a médica quanto a de enfermagem [...]. (Vigor - P, enfermeira) 
No discurso abaixo a enfermeira fala sobre a política de avaliação da instituição, que seria uma forma de reconhecimento do trabalho de seus colaboradores:

A instituição em si não tem uma política de avaliação do servidor funcionário, mas eu acho que a gente tem que ter meios para que a gente consiga avaliar e ser avaliado, e esses meios, não podem ser assim, "ah, como é que eu tô" só no diálogo, eu acho que tem que ter uma coisa mais oficial, ter alguma coisa escrita sobre isso [...]. (Carisma - P, enfermeira)

Os enfermeiros como chefias de equipe, também são grandes aliados nesse processo de reconhecimento da sua equipe, conforme os relatos abaixo:

Acho que é valorizar primeiro a equipe, né? Sempre dizer que por mais que esteja dificil, estamos em poucos, mas o serviço é de qualidade [...]. (Vigor - $\mathrm{P}$, enfermeira)

O que a gente faz é ressaltar, fortificar as qualidades que eles têm, [...], e o quanto o serviço deles é importante para a instituição, para a equipe e principalmente para o foco principal que é o paciente criança [...]. (Verdade - F, enfermeira)

Além do reconhecimento os enfermeiros sentem necessidade de mais autonomia, conforme ilustra $o$ discurso a seguir:

Você quer fazer além do que vocêfaz e muitas vezes você não consegue, por quê? Vários problemas, às vezes de hierarquia, que você é enfermeiro, mas que você quer fazer a diferença, quer montar protocolos, quer colocar aquele teu conhecimento em prática, e às vezes você é tolhido em realizar este procedimento, porque você tem que passar primeiro pela chefia médica, que falam que às vezes não é nessa hora vamos aguardar mais um tempo, então é você ter, essa dinâmica de poder fazer além, a mais, pelo teu conhecimento, acho que você conhece, tem estudo pra isso, tem conhecimento cientifico para colocar em prática e não ficar guardado, e essa é às vezes a grande dificuldade que a gente tem, que você quer fazer, mas é travado [...]. (Vigor - P, enfermeira)

Estratégias que favoreçam a satisfação no trabalho da equipe de enfermagem - Unidade de Registro 6: Promoção de reuniões para compartilhar informações, ouvir a equipe, sendo os funcionários colaboradores junto aos enfermeiros nos processos de decisões com os superiores.

A equipe de enfermagem reforça a necessidade de serem vistos como seres que cuidam de pessoas que apresentam questões importantes que devem ser contempladas e expostas aos demais membros, para que se possa desempenhar um trabalho de qualidade na organização hospitalar, conforme os discursos abaixo:

Teria que estar sempre tendo diálogo, reuniões e expondo o que está acontecendo realmente, o que pode ser feito e colocar, que geralmente coloca regras, mas colocar um objetivo melhor que todo mundo possa cumprir [...]. (Sensibilidade - F, técnica de enfermagem)

Outra questão também que é importante é a participação nas decisões, nas reuniões, nas comissões, enfim que necessitem da nossa votação e da opinião do trabalhador em relação ao serviço, que ele tem que estar ativo para mostrar como que é a realidade do serviço, se é adequado ou não [...]. (Alegria - P, auxiliar de enfermagem)

Os profissionais de enfermagem sentem necessidade desta educação contínua realizada pelos enfermeiros, conforme demonstram os discursos abaixo:

Eu acho que assim um pouco mais de educação continuada na unidade isso faz com que se minimize certos fatores estressantes que a gente pode encontrar, assim, por esquecimento mesmo, vício, hábito, trabalhar sempre dessa maneira [...]. (Carisma - P, enfermeira)

Eu acho que, dando assim mais cursos, é que assim $e ́$, eles tinham que fazer ainda mais [...] a gente acaba esquecendo alguns, né, então eu acho que a gente sempre tem que estar relembrando [...]. (Felicidade - P, auxiliar de enfermagem)

\section{DISCUSSÃO}

Os baixos salários oferecidos nas organizações hospitalares são decorrentes da baixa valorização do trabalho manual e da conotação caritativo-religiosa que ainda as acompanha ${ }^{(3)}$. A satisfação no trabalho envolve a necessidade de segurança relacionada à condição de trabalho oferecida. Outro fator importante que acaba desmotivando os funcionários é quanto ao local de descanso para aqueles que fazem plantão de 12 horas 
e a escala de folgas.

Um indivíduo, ao trabalhar em determinado local, espera encontrar recursos que permitam a realização de seu trabalho, como a adequação de recursos humanos, materiais e relações favoráveis estabelecidas neste ambiente. Essa realidade vivenciada também é significativa para a equipe de enfermagem, pois ela permanece parte de sua vida no local de trabalho e este deveria proporcionar-lhe oportunidade de desempenhar suas funções num ambiente que tivesse recursos humanos adequados, estrutura física e material apropriado.

A equipe de enfermagem se submete a esse processo de onde lhe é tirada a capacidade de agir de maneira mais integral, de opinar no sentido de obter melhorias, de questionar enfim. O enfermeiro raramente participa das discussões que envolvam mudanças na dinâmica do trabalho, que possibilitem melhores condições ${ }^{(3)}$.

A motivação é o resultado de fatores intrínsecos e extrínsecos, como o ambiente de trabalho, o trabalho em si, e principalmente as relações desenvolvidas entre chefes e subordinados e entre os subordinados. Cada funcionário em seu ambiente de trabalho deve ser reconhecido como um indivíduo único, dotado de capacidades e dificuldades, e, motivado por diferentes fatores.

A enfermeira Vigor expressa um desejo de poder manifestar-se, expor ideias que, em seu modo de entender, poderão ajudar a melhorar o trabalho e trazer benefícios para a enfermagem e para a assistência prestada aos pacientes. A valorização e o reconhecimento do trabalho executado são de grande importância para o estímulo da motivação, visto que uma vez implementado o indivíduo sente vontade de realizar bem o seu trabalho, esta vontade de trabalhar produtivamente é de grande importância para a enfermagem, uma vez que se trata de uma profissão cujas ações estão voltadas para o cuidado com o paciente, se o funcionário está desmotivado com o seu trabalho isto se refletirá na forma como cuida do paciente ${ }^{(4)}$.

A enfermeira acha necessária uma política de avaliação de desempenho do funcionário, um incentivo por parte dos gestores. Assim, os membros da equipe ficam cientes de como estão desempenhando seu trabalho e se têm algo a melhorar. Nas instituições hospitalares isso pode ser empregado como uma avaliação institucional ou também feedback. Em administração, feedback é o procedimento que consiste no provimento de informação a uma pessoa sobre o desempenho, conduta, ou ação executada por esta, objetivando reorientar ou estimular comportamentos futuros mais adequados. A satisfação profissional também pode ser estimulada através de estratégias que maximizem o comprometimento, a motivação e o reconhecimento do trabalho desenvolvido. Inspirar os profissionais no trabalho em equipe ou individual garante a conquista de melhores resultados ${ }^{(5)}$.

De uma maneira geral, o ser humano gosta de ser elogiado, isso traz estímulos emotivos para a sua vida. Um estímulo positivo, um agradecimento, um cumprimento pelo resultado na execução de uma tarefa, uma palavra de ânimo, entre outros, são atos capazes de transformar o cotidiano do trabalho da equipe, favorecendo o desenvolvimento das tarefas que realizam ${ }^{(3)}$.

Com isso vemos que a função dos enfermeiros é extremamente estressante, uma vez que o profissional possui muita responsabilidade no desenrolar de suas atividades diárias com condições de trabalho por vezes deficiente, e em contrapartida não possui a autonomia ou mesmo poder de decisão compatível com as suas responsabilidades perante a organização.

Os discursos demonstram sentimento favorável à aplicabilidade de momentos de conversas, reuniões, como fator de alivio de tensões e estresse, promovido por meio de momentos de diálogo, compartilhando informações, opiniões diferentes, esclarecendo dúvidas, se tornando também um momento de descontração da equipe, podem juntos apontar problemas e buscar soluções. Quando existem momentos assim que fortalecem o grupo, o trabalho em equipe, a amizade, o companheirismo são momentos importantes, pois propiciam o compartilhar de experiências, vivências e conhecimentos e proporcionam o estabelecimento da confiança entre os membros da equipe, conhecendo as características individuais e do grupo, possibilitando que o trabalhador expresse seus sentimentos, necessidades, dificuldades, dúvidas, dentre outros, para que possa haver trabalho solidário em equipe, mais tranquilo e prazeroso ${ }^{(6)}$.

O papel do enfermeiro diante da equipe é de extrema importância, pois ele precisa conhecer sua equipe, ter atitudes que a motivem em suas atividades, atuando de forma a amenizar o desgaste e a tensão que o trabalho de enfermagem em UTI demanda. Ao atuarmos dentro de uma UTI, deparamo-nos com intensa atividade física e elevado grau de estresse emocional, consequência do contato permanente com alta tecnologia que mascara a relação pessoa a pessoa, com situações de vida ou morte, com a ansiedade familiar, além da própria expectativa quanto à sua eficiência no desempenho profissional $^{(7)}$.

$\mathrm{O}$ enfermeiro com função administrativa que fo- 
caliza seu trabalho na equipe contribui para o alcance da satisfação da mesma, sendo um chefe participativo, influenciando diretamente as pessoas de sua equipe, não permeando desta maneira o individualismo, a competitividade ou o autoritarismo. Ele deve sempre desempenhar uma gerência voltada para as transformações, ou seja, inovadora, tendo como eixo norteador a

melhoria da qualidade da assistência de enfermagem e ainda buscar estratégias que possibilitem maior satisfação para a equipe de enfermagem no seu dia a dia de trabalho ${ }^{(8: 303)}$.

Na Unidade de Registro 6, Promoção da educação continuada da equipe, sobre temáticas direcionadas ao aprimoramento do cuidado de enfermagem, as atividades de educação continuada efetivamente desenvolvidas constituem-se em uma das formas de assegurar a manutenção da competência da equipe de enfermagem em relação à assistência de enfermagem. A educação continuada perpassa o profissional como forma de estímulo e motivação daqueles por ele assistido, para manifestarem também as experiências de autonomia, elevação da auto-estima e desenvolvimento pessoal. Entendendo, que a educação continuada pode possibilitar a melhora no relacionamento entre cliente, família e equipe, assim como na compreensão da doença, devido ao encorajamento da aquisição de conhecimento, despertando o autoconhecimento no profissional ${ }^{(9)}$.

Diante deste contexto, destaca-se a importância do enfermeiro compreender que os fatores motivacionais atuam diretamente na qualidade de vida dos funcionários e a qualidade dos produtos ditos como força motriz, é ela que impulsiona o desempenho de toda a equipe ${ }^{(10)}$. Pode-se dizer que o aprendizado consiste em uma ferramenta capaz de impulsionar o crescimento organizacional, entretanto, para que isso realmente aconteça não basta investir apenas no aprimoramento profissional do líder, mas também no desenvolvimento dos colaboradores, ainda mais na enfermagem, visto que seu processo de trabalho é estruturado de maneira coletiva ${ }^{(4)}$.

Os enfermeiros também podem criar um clima motivador sendo um modelo positivo e entusiasmado no ambiente de atuação clínica. Talvez o papel mais importante do líder em relação ao empregado sem motivação seja o de servir de modelo. Os líderes devem associar-se a um sistema de apoio profissional na busca de reforço positivo, informação e orientação no desenvolvimento profissional ${ }^{(11)}$.

\section{CONSIDERAÇÕES FINAIS}

É possível afirmar que houve a compreensão da extensão e da complexidade que envolve ser profissional de enfermagem atuante em UTI. Os diversos problemas e dificuldades frente às condições laborais da equipe de enfermagem levam a refletir na relação dialógica entre cuidar e ser cuidado: por um lado, encontrava-se o paciente que necessita de assistência pela equipe de forma integral, nas suas necessidades bio-psico e sócio espirituais, por outro, encontram-se os profissionais que também devem ser vistos na integralidade de suas necessidades e que, o trabalho pode ser percebido de diferentes maneiras considerando-se que cada um tem a sua concepção de mundo, suas aspirações, suas tristezas e suas alegrias.

Neste contexto, a figura do líder é de grande importância para o desenvolvimento da motivação da equipe de enfermagem, pois é ele quem irá valorizar a sua equipe, considerando-os indivíduos competentes, criativos e acima de tudo capazes de desenvolver um trabalho com qualidade, proporcionando condições de satisfação no trabalho para esses profissionais, o que geraria uma melhor qualidade de assistência aos usuários, bem como a promoção da saúde do trabalhador. Como proposta os autores acreditam que as instituições devem proporcionar ambiente de acolhimento, valorização, motivação e envolver o funcionário nos processos decisórios factíveis, dando autonomia na execução das tarefas relacionadas à sua função.

\section{REFERÊNCIAS}

1. Lima AFC e Kurganct P. Indicadores de qualidade no gerenciamento de recursos humanos em enfermagem. Rev. bras. enferm. [Internet] 2009;62(2) [acesso em 01 set 2010]. Disponível: http://dx.doi.org/10.1590/S003471672009000200010

2. BardinL. Análise de conteúdo. Portugal: Edições 70;2009.

3. Neumann VN. Qualidade de vida no trabalho: percepções da equipe de enfermagem na organização hospitalar [dissertação]. Belo Horizonte (MG): Universidade Federal de Minas Gerais; 2007 [Internet] [acesso em 11 jun 2011]. Disponível: http://pt.scribd. com/doc/55654446/12/Reconhecimento-forca-quemove-o-trabalho

4. Amestoy CS, Trindade LL, Waterkemper R, Heidman ITS, Boehs AE, Backes VMS. Liderança dialógica nas instituições hospitalares. Rev. bras. enferm. 2010;63(5):844-7. 
5. Heep RLS. O cuidado da equipe de enfermagem em UTI: a interface entre o prazer e o sofrimento [monografia]. Curitiba (PR): Faculdades Pequeno Príncipe; 2010.

6. Dejours C. Subjetividade, trabalho e ação. Rev. Prod. [Internet] 2004;14(3) [acesso em 04 nov 2010]. Disponível: http://dx.doi.org/10.1590/S010365132004000300004

7. Costenaro RGS. Ambiente terapêutico de cuidado ao recém-nascido internado em UTI neonatal. Santa Maria: Palotti; 2001.

8. Santini AM, Costenaro RGS, Medeiros HMF, Zaberlan C. Estresse: vivência profissional de enfermeiras que atuam em UTI neonatal. Cogitare enferm. [Internet] 2005;10(3) [acesso em 26 nov 2011]. Disponível: http://ojs.c3sl.ufpr.br/ojs2/index.php/cogitare/article/ view/5388/3964

9. Sardinha LP, Gonçalves LC, Costa D, Tavares T, Melo CM, Cavalcanti D et al. Educação permanente, continuada e em serviço: desvendando seus conceitos. Rev. Enfermería Global. [Internet] 2013;(29) [acesso em 18 mai 2013]. Disponível: http://scholar.google.com.br/ scholar?hl=ptBR\&q=Educa $\% \mathrm{C} 3 \% \mathrm{~A} 7 \% \mathrm{C} 3 \% \mathrm{~A} 3 \mathrm{o}+$ per manente $\% 2 \mathrm{C}+$ continuada $+\mathrm{e}+\mathrm{em}+$ servi $\% \mathrm{C} 3 \% \mathrm{~A} 7 \mathrm{o} \% 3$ $\mathrm{A}+$ desvendando + seus + conceitos $\& b \operatorname{bnG}=\& 1 \mathrm{r}=$

10. Regis V, Ladeia LF. Satisfação no trabalho da Enfermagem: pela construção de um conceito [tese]. Rio de Janeiro (RJ): Universidade Federal do Rio de Janeiro; 2011.

11. Marquis BL, Huston CJ. Administração e liderança em enfermagem. $4^{\mathrm{a}}$ ed. Porto Alegre: Artmed; 2010. 